\title{
Electronics in the Life Sciences
}

\section{STEPHEN YOUNG}

Lecturer in Zoology

Imperial College, London 
All rights reserved. No part of this publication may be reproduced, in any form or by any means, without permission.

First edition 1973

Reprinted (with corrections) 1975

Published by

THE MACMILLAN PRESS LTD

London and Basingstoke

Associated companies in New York Dublin

Melbourne Johannesburg and Madras

ISBN 978-0-333-14271-4 ISBN 978-1-349-86183-5(eBook)

DOI 10.1007/978-1-349-86183-5

Text set in 10/12 pt. IBM Press Roman

The paperback edition of this book is sold subject to the condition that it shall not, by way of trade or otherwise, be lent, resold, hired out, or otherwise circulated without the publisher's prior consent in any form of binding or cover other than that in which it is published and without a similar condition including this condition being imposed on the subsequent purchaser. 


\section{Preface}

Complex electronic instrumentation is rapidly becoming ubiquitous in biological laboratories. Animal nervous systems use small electrical signals to transfer information and to compute strategies, and those studying them need electronic amplifiers and dataloggers. Many biochemical and physiological data are most readily measured and recorded if they can first be reliably transformed into electrical signals by transducers. Temperature changes, illumination changes, and movements of an animal are all typical examples. Moreover it is often necessary to maintain the environment of an experimental animal, plant, or biochemical system in conditions of constant and measured temperature, humidity and illumination, or to provide it with stimuli changing in a stereotyped fashion. All these require electronic servomechanism control systems.

Electronic event recognisers coupled to datalogging systems have extended the range of experimentation to situations in which the rates at which events occur are too fast or too slow for the unaided human observer: if signals arrive at more than two per second human observers soon begin to make errors, and similarly if the gaps between signals are of more than two or three minutes the observer simply drops off to sleep.

I have the strong feeling that these complex electronic systems, however indispensable, are disliked and distrusted by many biologists. There is a considerable nostalgia for the paper, pencil, string and sealing wax phase even among those too young to have any personal experience of it, and a tendency to treat the electronics with alternating contempt (a good thump when it doesn't work) and exaggerated respect (summoning the firm's representative every time a minor adjustment to a knob on the front panel is needed). I think it's probably worth making clear at this point that no well-designed piece of electronics can ever be damaged by any combination of settings of the knobs on its front panel, and that the best way of finding out the functions of the control knobs in behavioural rather than electronic terms (knobs tend to be labelled in terms which tell you what they do to circuits rather than how this affects the final output of the machine) is to set the thing going and to make small adjustments to each control in turn and to watch what happens. 
But even those who have satisfactorily come to terms with their instruments, and who have opted for the strategy of buying as much as possible of their equipment readymade still tend to come up against difficult electronic problems when it comes to connecting the various boxes together ('interfacing'). It is frequently necessary to attenuate or amplify voltages, to change the length of pulses, and so forth.

Hence many students and research workers in biology and medicine now require a working knowledge of electronics, and I have tried to arrange this book to cater for a wide variety of their needs. The student who requires a textbook to supplement a course, or the research worker with little or no previous experience in electronics, can simply read the book straight through. The first four chapters supply a minimum of electronic theory, and the rest of the book deals with commonly used circuits, arranged in order of increasing conceptual difficulty. For the more experienced user, the electronic ideas are always introduced in the context of the practical applications listed as chapter headings, and so he should be able to find both the theoretical and practical information needed to build any given circuit within a few pages of text. However, neither of the superimposed arrangements corresponds to a rigorous ordering of circuits on an electronic basis, and so a schematic table of contents is provided which classifies every type of circuit in the book in a rational electronic scheme.

In addition to providing this basic information, I hope that I have also managed to demystify much of the electronic terminology which has crept insidiously into so much biological model building and theory forming. Everybody seems to be talking about positive and negative feedback, AC coupling, relaxation oscillators and the like, often without very much idea about the very precise engineering definitions of these terms, and certainly without the wealth of technological examples which have made engineering examples so fruitful in the past.

I have actually built all the circuits in this book, and they do all work. However it is difficult to offer an unconditional guarantee, and I should be very interested to hear of any problems. It is very hard to remember the exact provenance of all the circuits, and I must apologise to anyone whose 'original' circuit I have unwittingly borrowed. The only two electronics books I use frequently are:

\section{T. D. Towers Elements of Transistor Pulse Circuits \\ P. E. K. Donaldson Electronic Apparatus for Biological Research}

All my electronic thinking has been influenced by Steve Salter's teaching, and my approaches to instrumentation problems stem largely from discussions and co-operation with Anthony Downing, Ian Fosbrooke, Richard Gregory, Jim Howe, and John Moorhouse. 


\section{Contents}

1. The Multimeter. Amps; Volts; Ohms; Ammeters and Voltmeters;

AC Ranges

2. The Oscilloscope. Signal sources; Oscilloscope controls; AC-coupling

- the capacitor; Oscilloscope display systems - the storage oscilloscope

3. Power Supplies. Batteries; AC mains; Transformers; Diodes; Peak and average voltages; Capacitative smoothing; Regulation

4. Amplifying Small Electrical Signals. The good amplifier; Feedback;

Electronic negative feedback; Noise and the phase-sensitive amplifier; Physiological amplifiers

5. Datalogging. Data-reduction; Electronic event recognisers; Counters; Tape recorders; Computer datalogger

6. Controlling Stimuli and Measuring Responses. Light; Heat; Movement; Humidity; Electrical responses

7. Automated Experiments. Building blocks for automated experiments; Programmed stimulus presentation; Interactive stimulus presentation.

8. Pulse Circuits. The delay circuit or monostable; The multivibrator; The bistable (flip-flop)

Manufacturers and Suppliers

Glossary

Index 


\section{Circuit List}

PASSIVE (NO POWER SUPPLY)

Page

Voltage

divider

$\prod_{R_{2}}^{R_{1}}$-Out $V_{\text {out }}=V_{\text {in }} \cdot \frac{R_{2}}{R_{1}+R_{2}}$

Wheatstone bridge

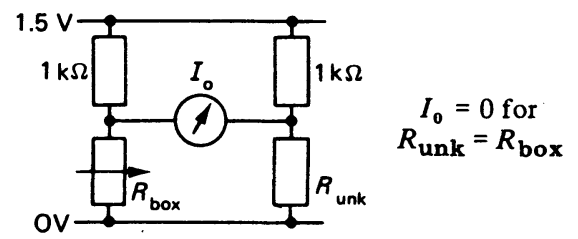

RC filters
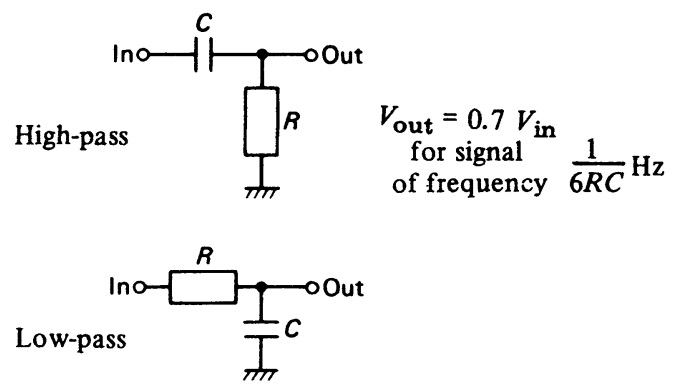

Half-wave rectifier
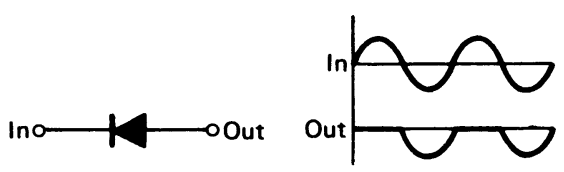

Full-wave rectifier

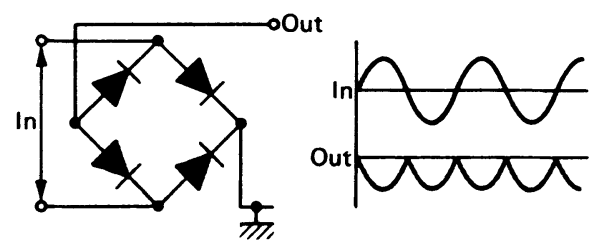

Diode pump

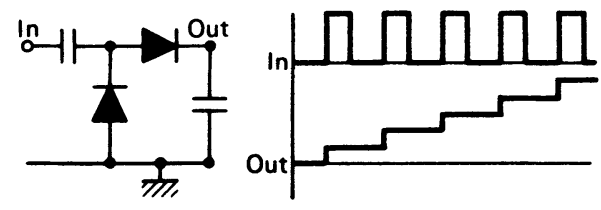




\section{ACTIVE}

Amplifiers and Integrators

Page

One-transistor amplifiers Common collector $V_{\text {out }}=12-100 I_{\mathrm{i}} R$
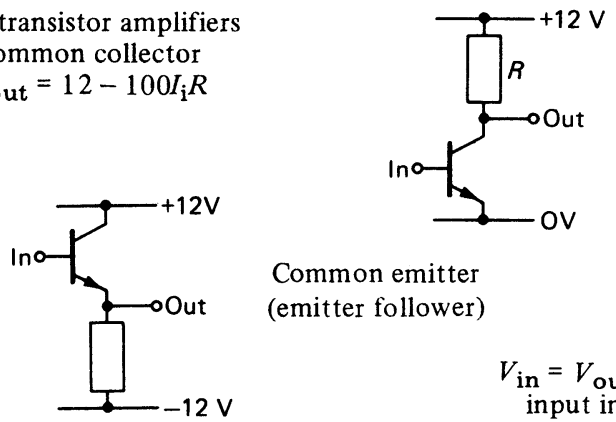

Common source, FET version

Common emitter

(emitter follower)

$V_{\text {in }}=V_{\text {out }}$, but high

input impedance

Current

amplifier

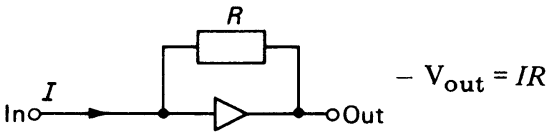

Voltage

amplifier

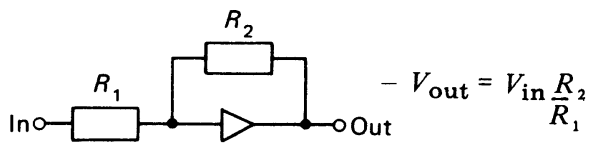

Adder
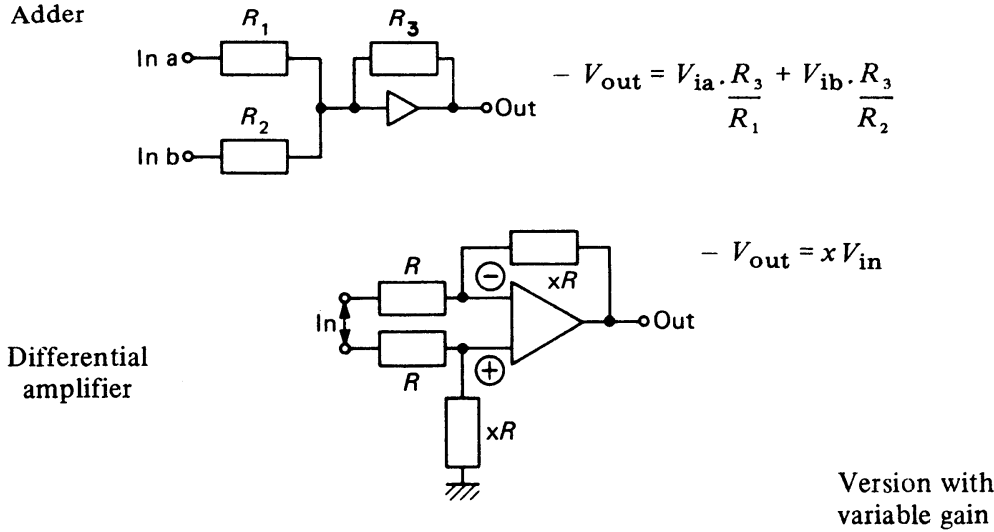

Voltage

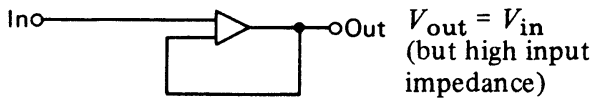

follower impedance)

Integrator

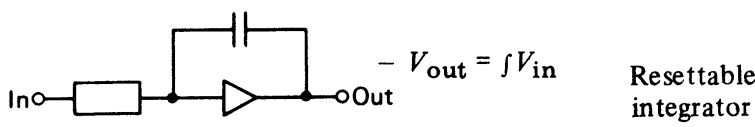




\section{ACTIVE}

Switches and Pulse Circuits

Page

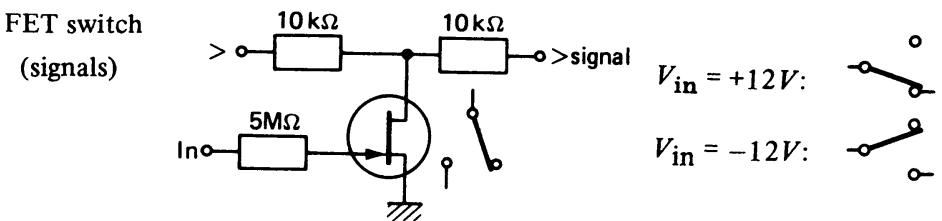

Transistor switch

(currents)
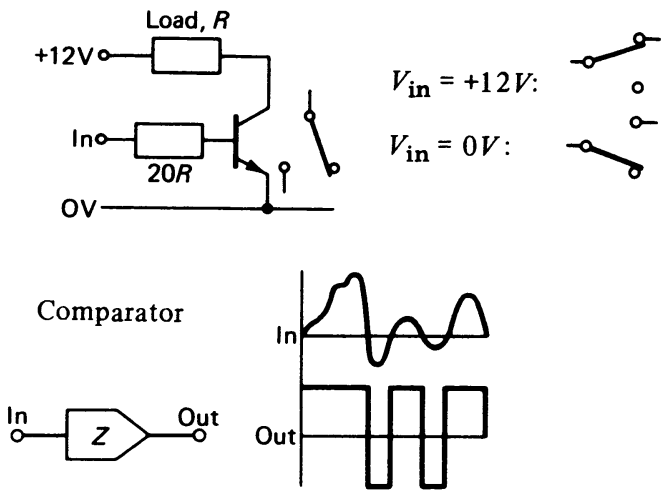

Monostable

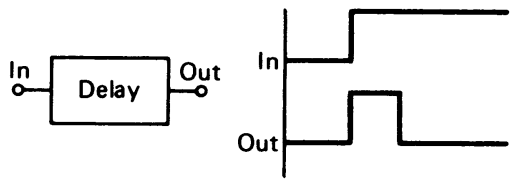

Square-wave oscillator

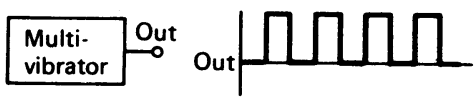

Bistable
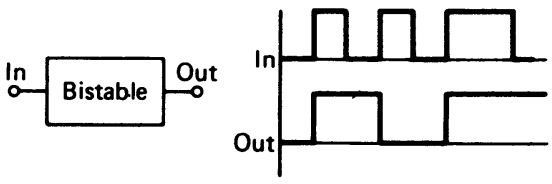

Sample and hold
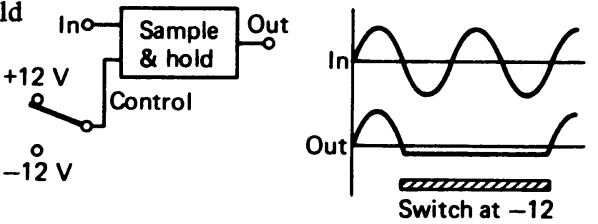

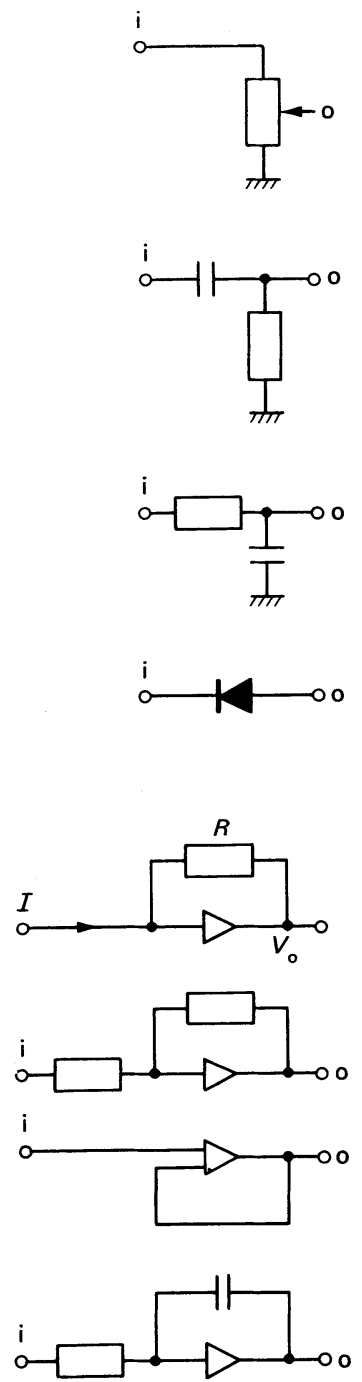
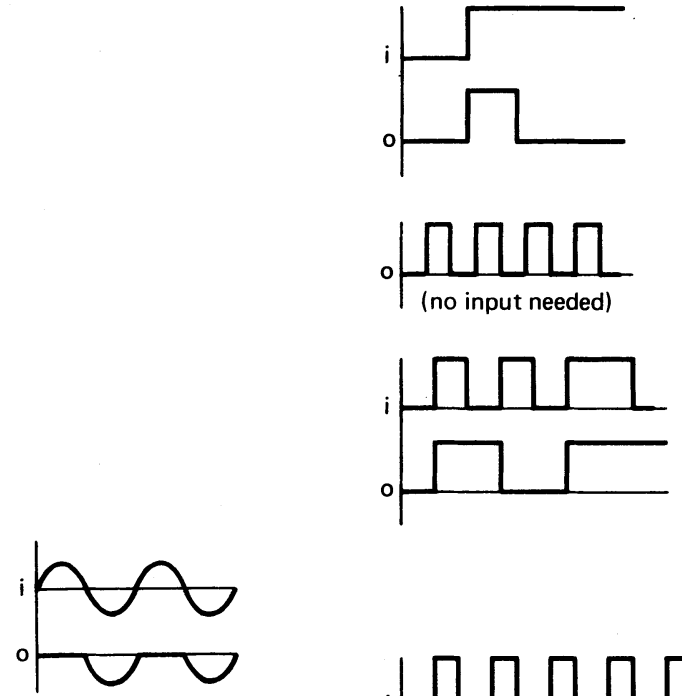

$$
V_{\mathrm{o}}=I R
$$

$$
V_{0}=x V_{i}
$$$$
v_{0}=V_{i}
$$

(but high input impedance)
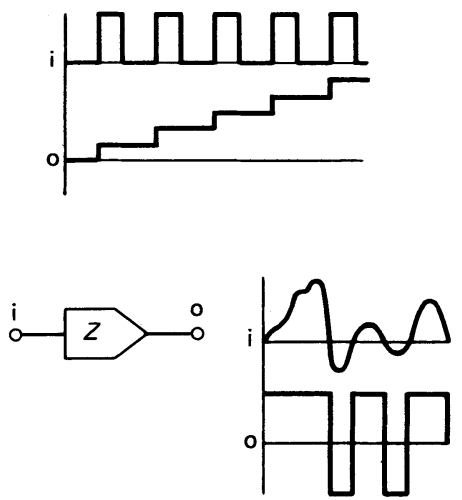

$$
v_{0}=\int v_{i}
$$

